\title{
Effect of Antibacterial Enoxacin on the Properties of Injectable Nano-hydroxyapatite/Polyurethane Cement for Bone Repairing
}

\author{
Jinzheng Zhang ${ }^{1} \cdot$ Xiaoyu Lei ${ }^{1}$. Jiajing Tang ${ }^{1} \cdot$ Jie Chen $^{1} \cdot$ Qing Zhao $^{1} \cdot$ Wei Fang ${ }^{1}$. Yinglong Zhang ${ }^{1} \cdot$ Yubao Li $^{1}$. \\ YiZuo' ${ }^{1}$
}

Received: 2 September 2021 / Revised: 4 December 2021 / Accepted: 14 December 2021 / Published online: 21 February 2022

(c) The Author(s) 2022

\begin{abstract}
Biomaterial-associated infection (BAI) is a kind of serious post-operative complication in orthopaedic surgery. Antibioticloaded bone cement shines a light on BAI prevention for convenient manipulation and complex filling. To this aim, we designed an antibacterial bone cement based on Nano-hydroxyapatite/Polyurethane (PUHA) loading with antibiotic Enoxacin (EN). The distinct shear-thinning behavior of the prepolymers was observed, indicating a good injectability. The PUHA bone cement possessed a suitable curing speed, and the addition of EN might slightly expedite the curing process and enhance the mechanical properties. The EN release profile indicated that the EN-loaded bone cement could reach the minimum inhibitory concentration in $2 \mathrm{~h}$, and sustainedly released EN for almost 8 days, exhibiting an antibacterial delivery potential. Antibacterial test further confirmed the antibacterial ability of EN-loaded bone cement is in a dose-dependent manner. However, the osteogenic performance of drug-loaded bone cement with high dosage is not as good as antibacterial activity. When the EN concentration of antibacterial cement was lower than $32 \mu \mathrm{g} \cdot \mathrm{mL}^{-1}$, the proliferation and osteogenic differentiation of rat mesenchymal stem cells could be significantly promoted. Overall, this study verified the potential of the EN-loaded PUHA bone cement in anti-infection and osteogenesis for bone repairing.
\end{abstract}

Keywords Antibacterial bone cement · Nano-hydroxyapatite/polyurethane · Enoxacin · Shear-thinning behavior · Osteogenesis

\section{Introduction}

In the aging society, BAI is extremely difficult to prevent and cure due to the fracture fixation meets with osteoporosis treatment $[1,2]$. BAI is a kind of acute complication triggered mostly by biofilms on implants in orthopaedic surgery, which could lead to non-union, loss of function, and even amputation [2]. It was reported that the BAI rate was between 2.6 and $45 \%$ if tibial plateau fractures managed with Open Reduction and Internal Fixation (ORIF) in bone fracture fixation clinically [3,4]. A new type of treatment strategy that antibiotic-loaded bone cement was covered on intramedullary nail achieved significant effect for deep infection after ORIF of ankle fractures [5]. Bone cement can form

Yi Zuo

zoae@scu.edu.cn

1 Research Center for Nano-Biomaterials, Analytical and Testing Center, Sichuan University, Chengdu 610064, People's Republic of China a strong bond in situ with bone tissue to create a mechanically stable interface under the influence of tensile, compressive, and shear forces [6]. Furthermore, bone cement has the capacity to fill bone cavities with complicated geometric shapes on the foundation of excellent liquidity and fix grafts with low risk of refractures caused by stress shielding [7]. Thus, injectable bone cement is attracting more attention from many researchers as a kind of local drug delivery vehicle for BAI prevention.

For now, the mainly bone cement were Polymethyl Methacrylate (PMMA) and Calcium Phosphate Cement (CPC) in clinic. However, both these bone cements had their shortcomings during clinical use. PMMA has undergone an exothermic polymerization reaction that can cause terrible local thermal necrosis during the curing process [8]. What's worse, exothermic polymerization makes some temperature-sensitive antibiotics inactivate, which limits the choice of antibiotics [9]. PMMA causes aseptic loosening due to no bioactivity, and the toxicity of its liquid monomer seriously affects the therapeutic effect [10]. For 
calcium phosphate cement, high bioactivity is preferable for the bone regeneration without heat released during the curing process. However, its curing time was long and the adhesion was relatively poor [11]. Meanwhile, inappropriate mechanical strength and poor fixation performance of CPC in biological environments can exacerbate bone destruction [12]. Therefore, CPC mainly be applied in non- or moderate load-bearing sites. Hence, it is urgent to modify current bone cement $[13,14]$ or develop a different bone cement system with good mechanical strength, biocompatibility and anti-infection.

Polyurethane (PU), a kind of polymer material with adjustable properties, has attracted much attention from many researchers $[15,16]$. There were plenty of strategies to design PU into bone cement, such as one-component PU, two-component PU, and many more [17]. Among them, two-component (component A and component B) system has been often used to design bone cement based on PU [18]. Our previous study incorporated nano-hydroxyapatite (n-HA) nanoparticles into PU to prepare PUHA cement [19]. The setting time and mechanical properties have been largely affected by different contents of nano particles. Although the PUHA cement has promising osteogenesis for the addition of high bioactive n-HA, lack of anti-infection limits its clinical application. Silver has been added in the injectable PU system to provide effectively antimicrobial property [20]. However, the poor cellular viability of $\mathrm{Ag}^{+}$is a major obstacle for the PU cement used in clinic.

Generally speaking, antibacterial activities in biomedical perspective are related to compounds or elements that locally retarding bacteria or killing bacterial, without being in general toxic to surrounding tissues [21]. Most current antibacterial agents, available in medical industries are chemically modified from natural compounds [22], known as antibiotics. It was noteworthy that the antibacterial effect of each antibacterial agent was depending on the species of bacterial strain and its effective mechanism [23]. By and large, BAI was triggered by lots of pathogens including genus Staphylococcus, Acinetobacter and Escherichia, specifically Staphylococcus aureus [24]. Herein, EN is a third-generation fluoroquinolone broad-spectrum antibiotic, especially against Gram-positive bacteria, such as Staphylococcus aureus [25]. It can form a ternary complex of drug-enzyme-DNA that once be trapped, disrupting DNA replication and triggering cell death mechanisms [26]. The antibacterial mechanism of EN help it can kill Staphylococcus aureus with a concentration $\leq 0.8 \mu \mathrm{g} \cdot \mathrm{mL}^{-1}$ [27]. The Minimal Inhibitory Concentration (MIC) of EN is far below $\mathrm{Ag}, \mathrm{Au}$ and other inorganic antibacterial agent [23]. Thus, EN is an appropriate choice of antimicrobial agents applied for BAI.

In this study, we incorporated the antibacterial drug EN into PUHA composite to prepare an injectable antibacterial bone cement for the infection prevention in bone repairing. First, we prepared EN-loaded PUHA and investigated their rheological properties, isocyanate group $(-\mathrm{NCO})$ conversion rate, chemical construction, morphology, mechanical properties and drug release behavior of the bone cement. To verify the antibacterial property of EN-loaded PUHA, antibacterial experiment was performed to investigate the inhibitory effect of bone cement on Staphylococcus aureus (Gram-positive bacteria) and Escherichia coli (Gram-negative bacteria). Finally, the cytotoxicity and osteogenic differentiation properties of bone cement were evaluated by rat Bone Marrow mesenchymal Stem Cells (BMSCs) (Fig. 1).

\section{Materials and Methods}

\subsection{Materials}

EN, Isophorone Diisocyanate (IPDI), Polytetramethylene Ether Glycol (PTMEG, $M_{\mathrm{n}}=2000$ ), mannitol, and Polyethylene Glycol $\left(\mathrm{PEG}_{600}, M_{\mathrm{n}}=600\right)$ were purchased from Aladdin Industrial Corporation (Shanghai, China). Stannous salt was bought from J \& K Scientific Ltd (Beijing, China). The n-HA particles were prepared through a chemical precipitation method, as reported in our previous study [28], and they were dried at $108^{\circ} \mathrm{C}$ for $2 \mathrm{~h}$ in an electro-thermostatic blast oven. The above reagents are all analytical reagents.

\subsection{Fabrication of Polyurethane-Based Bone Cement}

\subsubsection{Component A: Injectable Prepolymer}

Firstly, PTMEG and mannitol were added to a three-necked round bottom flask, stirred with a stir rod under nitrogen atmosphere at $70{ }^{\circ} \mathrm{C}$ for $30 \mathrm{~min}$, and then n-HA was added and dispersed for $1 \mathrm{~h}$. Second, IPDI was subsequently added, and the pre-polymerization process was approximately $5 \mathrm{~h}$ at $70{ }^{\circ} \mathrm{C}$. Finally, EN was added and stirred under nitrogen atmosphere at ambient temperature for $1 \mathrm{~h}$. The isocyanate index (stoichiometric ratio of $\mathrm{NCO} / \mathrm{OH}$ ) was set at 1.5. Four types of bone cement prepolymers were fabricated as preceding steps and the formulation of each compound is shown in Table 1.

\subsubsection{Component B: Curing Reagent}

The curing reagent was acquired by mixing stannous salt and $\mathrm{PEG}_{600}$ at a mass ratio of 1:3. And then, homogeneous curing reagent was obtained through ultrasonic dispersion for at least $20 \mathrm{~min}$. 
Table 1 Formulation of four different bone cement prepolymers $(n=5)$

\begin{tabular}{llllll}
\hline $\begin{array}{l}\text { Material abbre- } \\
\text { viations }\end{array}$ & PU (wt \%) & n-HA (wt \%) & EN (wt \%) & $\begin{array}{l}\text { Drug-loading } \\
\text { efficiency }(\%)\end{array}$ & $\begin{array}{l}\text { Encapsula- } \\
\text { tion rate } \\
(\%)\end{array}$ \\
\hline PUHA & 80 & 20 & 0 & - & - \\
UAE-1 & 79 & 20 & 1 & $0.95 \pm 0.04$ & $94.0 \pm 1.2$ \\
UAE-2 & 78 & 20 & 2 & $1.94 \pm 0.08$ & $96.8 \pm 1.7$ \\
UAE-3 & 77 & 20 & 3 & $2.98 \pm 0.12$ & $95.9 \pm 1.5$ \\
\hline
\end{tabular}

\subsubsection{Polymer Preparation}

According to ISO 5833-2002 (Implants for surgery - Acrylic resin cement), component $\mathrm{A}$ and component $\mathrm{B}$ at a volume ratio of 25:1 were mixed at ambient temperature, and then the homogeneously mixed pastes were injected into a Teflon mold $\left(\phi 6 \mathrm{~mm} \times 12 \mathrm{~mm}^{3}\right.$ ) to cure in a $37{ }^{\circ} \mathrm{C}$ cabinet for $48 \mathrm{~h}$.

\subsection{Characterization of Bone Cement}

Rheological properties were measured using a rheometer (Discover HR-2, TA, USA). The storage modulus $\left(G^{\prime}\right)$ and loss modulus $\left(G^{\prime \prime}\right)$ of the mixture of component $\mathrm{A}$ and component $\mathrm{B}$ was measured at a frequency of $1.0 \mathrm{~Hz}$ at $37{ }^{\circ} \mathrm{C}$ during the curing process. The shear-dependence viscosity of four prepolymers of bone cement and component $\mathrm{B}$ was measured at $25{ }^{\circ} \mathrm{C}$ in a shear rate range between 0.1 and $200 \cdot \mathrm{s}^{-1}$.

The chemical shift of carbon in PUHA was characterized by $\mathrm{C}^{13}$ solid Nuclear Magnetic Resonance $\left(\mathrm{C}^{13}\right.$-NMR, AVANCE III-500 MHz, Bruker, Switzerland) using a $500 \mathrm{MHz}$ spectrometer for $\mathrm{C}^{13}$ nuclei at room temperature. The n-HA, PU and PUHA cement have been characterized by X-ray Diffraction (XRD, EMPYERAN, Panalytical, Netherlands) with $\mathrm{Cu} \mathrm{K} \alpha$ radiation. The conditions were at $40 \mathrm{kV}$ and $25 \mathrm{~mA}$. Scans and $2 \theta$ range was from 10 to $60^{\circ}$ at a step size of $0.03^{\circ}$. The chemical functional group of four bone cements and EN were investigated by Attenuated Total Internal Refraction Fourier Transform Infrared spectroscopy (ATR-FTIR, Thermofisher, Nicolet-5700). ATR-FTIR measurements of the compounds were performed using a universal ATR sampling accessory between 4000 and $400 \mathrm{~cm}^{-1}$. In addition, the -NCO conversion rate was tracked during the curing process every $10 \mathrm{~min}$ through ATR-FTIR. The n-HA powder were prepared in our lab according to the previous paper [28], which was characterized by Transmission electron microscopy (TEM, Tecnai, G2 F20, Hillsboro, OR, USA). In addition, a clearly observation of the dispersion of n-HA in the PU matrix, was sectioned by cryoultramicrotomy with a diamond knife at a $50 \mathrm{~nm}$ thickness.
Cross-linking is a crucial property for the cements formed in situ, which also means the stableness of the PU network. Therefore, the apparent density $(\rho)$, Swelling Rate $(S R)$ and Gel content $(G)$ of the cements were tested for the crosslinking evalution according to swelling equilibrium method and previous paper [29]. The cement samples ( 6 $6 \mathrm{~mm} \times 12$ $\mathrm{mm}^{3}$ ) were dissolved into absolute ethanol for $24 \mathrm{~h}$. In addition, $\rho, S R$ and $G$ were defined by the following Eqs. (1), (2), and (3), respectively:

$\rho=\frac{4 m_{d}}{\pi d^{2} h}$

$S R=\left(\frac{m_{s w}-m_{d}}{m_{d}}\right) \times 100 \%$

$G=\frac{m_{d}}{m_{0}}$

where $m_{s w}$ and $m_{d}$ are the samples quality of swelling state and dry state, respectively. $m_{0}$ is the $m_{s w}$ after vacuum drying at $37^{\circ} \mathrm{C}$ for $24 \mathrm{~h}$. " $d$ " and " $h$ "mean the diameter and high of samples. $\rho_{1}$ is the specific density of the ethanol $\left(0.789 \mathrm{~g} \cdot \mathrm{mL}^{-1}\right)$ and $\rho_{2}$ is the density of samples from Eq. (1).

According to ASTM D 5024-95 standard, the mechanical properties of the four types of cured bone cement were tested on samples with a size of $\phi 6 \times 12 \mathrm{~mm}^{3}$ through a mechanical testing machine (AUTOGRAPH AG-IC $20 / 50 \mathrm{KN}$, Japan). All the tests were conducted at the speed of $1 \mathrm{~mm} \cdot \mathrm{min}^{-1}$, and the load was applied until the specimen was compressed to approximately $50 \%$ of its original length at room temperature. The compressive modulus was calculated by the slope of linear change that appeared for the first time in the stress-strain curve. The compressive strength was calculated according to the following formula (4):

$\delta=\frac{p}{F}$

where $\delta, p$ and $F$ indicate the compressive strength, stress, and surface area, respectively. Five independent samples were tested for each group. 
The microstructure of PUHA, UAE-1, UAE-2 and UAE-3 cements were observed by Scanning Electron Microscopy (SEM, JSM-7500F, JEOL, Japan) in Back-Scattered Electron (BSE) mode. An Energy Dispersive Spectrometer (EDS, JSM-7500F, JEOL, Japan) was used on the surface of the samples to evaluate the distribution of the $\mathrm{Ca}$ and $\mathrm{P}$ elements. The brittle fracture surfaces of tested samples were obtained by liquid nitrogen and sputter-coated with gold before the examination. The X-ray Photoelectron Spectrometry (XPS, AXIS UltraDLD, UK) was selected to elucidate the presence of EN in the drug-loaded cements by means of observing the peak of $\mathrm{F}$ element in XPS spectra.

\subsection{In Vitro Drug Release and Antibacterial Assay}

In vitro drug release of different samples was carried out according to ISO 10993-12. Different samples $(n=5)$ were immersed in $10 \mathrm{~mL}$ DMSO/PBS $(v / v=1 / 200)$ medium with gentle agitation at $37{ }^{\circ} \mathrm{C}$, then $1 \mathrm{~mL}$ of medium taken out for analysis at different timepoints, which were $1 \mathrm{~h}, 2 \mathrm{~h}, 8 \mathrm{~h}$, $24 \mathrm{~h}, 48 \mathrm{~h}, 4 \mathrm{~d}, 7 \mathrm{~d}, 14 \mathrm{~d}$ and $30 \mathrm{~d}$. The content of EN was detected at $268 \mathrm{~nm}$ by ultraviolet-visible spectroscopy [30] (Shimadzu UV-VIS V-2401, Japan).

Staphylococcus aureus (S. aureus, CMCC (B) 26003) and Escherichia coli (E. coli, CMCC 44103) were chosen as standard bacteria to evaluate the antibacterial activity of PUHA and EN-loaded bone cement [31]. Both bacteria were grown aerobically in broth medium at $37{ }^{\circ} \mathrm{C}$. The test conditions of inhibition zone and antibacterial rate were as follows [32]:

(1) Zone of inhibition (ZOI): the disk-shaped samples $(\phi$ $6 \mathrm{~mm} \times 2 \mathrm{~mm}^{3}$ ) were placed on agar plates pre-inoculated and incubated at $37{ }^{\circ} \mathrm{C}$ for $24 \mathrm{~h}$.

(2) Antibacterial rate: the disk-shaped samples were incubated with $1 \times 10^{6} \mathrm{CFU} \cdot \mathrm{mL}^{-1}$ E. coli at $37{ }^{\circ} \mathrm{C}$ for $2 \mathrm{~h}$. After the incubation, the co-cultured bacterial suspensions were diluted by a tenfold dilution method to enumerate the bacteria. The antibacterial ability was recognized by Bacteriostasis Rate (BR), which was defined by the following Eq. (5):

$$
B R=\left(\frac{N_{0}-N_{1}}{N_{0}}\right) \times 100 \%
$$

where $N_{0}$ is the number of colonies for the control sample (PUHA), and $N_{1}$ is the number of colonies for UAE-1, UAE2, and UAE-3.

\subsection{In Vitro Cell Evaluation}

\subsubsection{Extract Solutions Preparation}

The extract solutions of EN-loaded bone cement were prepared according to ISO 10993-9. The disc samples $\left(\phi 6 \times 2 \mathrm{~mm}^{3}\right)$ were immersed in Alpha Minimum Essential Medium ( $\alpha$-MEM, Gibco) supplemented with $10 \%$ Newborn Calf Serum (NBCS) and 1\% penicillin/streptomycin. The surface area to extract medium ratio was $1.25 \mathrm{~cm}^{2} \cdot \mathrm{mL}^{-1}$, and the immersed samples were kept in a humidified atmosphere with $5 \% \mathrm{CO}_{2}$ at $37{ }^{\circ} \mathrm{C}$ for $48 \mathrm{~h}$. Then the extract medium was collected and refrigerated at $4{ }^{\circ} \mathrm{C}$.

\subsubsection{Cell Proliferation}

Sprague-Dawley (SD) rats were obtained from the DOSSY experimental animals Co, Ltd. The BMSCs were extracted from the femurs and tibiae of the SD rats weighing approximately $100 \mathrm{~g}$. The extraction was according to the normative procedure, which was approved by the Ethics Committee of Sichuan University. The third passage of the BMSCs were utilized in the experiments [33]. BMSCs $\left(1 \times 10^{4}\right.$ cells/well $)$ were equilibrated in $\alpha$-MEM medium and extract solutions of EN-loaded bone cement to evaluate cell proliferation. The cell proliferation was evaluated using a Cell Counting Kit-8 (CCK-8) kit (Sigma-Aldrich Co., St. Louis, MO, USA) on days 1, 4 and 7. A multi-label counter (Wallac Victor 31420, PerkinElmer Co., Waltham, MA, USA) was used to detect the absorbance value at $450 \mathrm{~nm}$. The morphology of live BMSCs was observed by a fluorescence microscope. Three samples were tested in each group.

\subsubsection{Cell Differentiation}

The activities of Alkaline Phosphatase (ALP) and Osteocalcin (OCN) are mostly used to assess osteogenic differentiation of the BMSCs, which were served as early osteogenesis [34] and terminal osteogenesis [35], respectively. In this study, Enzyme-Linked Immunosorbent Assay kits (ELISA, Wuhan Cloud-Clone Corp, CO., Wuhan, China) were employed to evaluate the ALP and OCN content of BMSCs [28]. The BMSCs $\left(8 \times 10^{3}\right.$ cells/well $)$ were seeded in $\alpha$-MEM medium and extract solutions to evaluate the ALP and OCN content on $7 \mathrm{~d}$ and $14 \mathrm{~d}$, respectively. 


\subsection{Statistical Analysis}

The data was expressed as the mean \pm Standard Deviation (SD). One-way Analysis of Variance (ANOVA) tests, together with a post-hoc Tukey's test was conducted using the SPSS (version 25.0) software (LEAD Technologies, Inc., Chicago, IL, USA) to examine the data by the following significance levels: $p<0.05, p<0.01$ and $p<0.001$, which represented statistically significant, very significant, and extremely significant values, respectively. $p>0.05$ indicated that there were no statistically significant values.

\section{Results and Discussion}

\subsection{Rheological Properties and Isocyanate Conversion Rate}

The advantage of injectable cement over other biomaterials is excellent fluidity and in situ curing characteristic, which could help bone cement fill irregular bone cavities and fix grafts. Thus, injectable bone cement is supposed to have an appropriate setting time so that the bone cement would have enough time long for clinical operation. Typically, the setting time for clinically available bone cement vary by between 5 and 15 min [36]. The intersections of $G^{\prime}$ and $G^{\prime \prime}$ in the curve demonstrated the gelation points, which can imply setting time to some extent [37, 38]. Therefore, it is worthwhile to explore the rheological properties of the bone cement. In addition, the $-\mathrm{NCO}$ conversion rate is tested to determine whether the addition of EN would affect the $-\mathrm{NCO}$ conversion rate.
For rheological analysis, storage moduli $\left(G^{\prime}\right)$ and loss moduli $\left(G^{\prime \prime}\right)$ of the mixture (component A and component B) implies the elastic nature and the viscous nature, respectively. As shown in Fig. 2a-d, at first, all mixtures exhibited fluidity, because $G^{\prime \prime}$ appeared to be greater than $G^{\prime}$. The intersections of $G^{\prime}$ and $G^{\prime \prime}$ in the curve exhibited at 21.13 min (PUHA), $16.68 \mathrm{~min}$ (UAE-1), $13.35 \mathrm{~min}$ (UAE2 ), and $11.83 \mathrm{~min}$ (UAE-3), respectively. With the proportions of EN increased, the curing time of mixtures became shorter, and the setting procedure was faster. The mixture of component A and component B would solidify when time went by. Therefore, the UAE- 2 and UAE- 3 both had suitable setting time.

As shown in Fig. 2e, the four types of bone cement prepolymers and component B exhibited distinctly shear-thinning behavior. Shear-thinning behavior conforms to the law of pseudoplastic flow of materials that help the mixture of component $\mathrm{A}$ and component $\mathrm{B}$ possess the desired flowability when it is injected in vivo. Furthermore, we tested the viscosity of three drug-loaded cement prepolymers which were in the range of $47-100 \mathrm{~Pa} \cdot \mathrm{s}$ in Fig. 2e. A previous study about a commercial PMMA cement found that the initial viscosity of bone cement would be better if the viscosity is in the range of 50-100 Pa.s [39], which could help the bone cements to prevent leakage while ensuring injectability. To sum up, the shear-thinning characteristic and the viscosity of the EN-loaded bone cement can meet the requirements of good injectability and proper curing time.

In Fig. $2 \mathrm{f}-\mathrm{i}$, the peak of isocyanate group decayed with the increasing cure time. The IR spectra presented a typical speeding up trend in different EN-loaded cements when they were consuming the $-\mathrm{NCO}$ groups. The relative
Fig. 1 Graphical abstract of injectable EN-loaded bone cement based on PUHA promoting osteogenesis and inhibiting bacterial

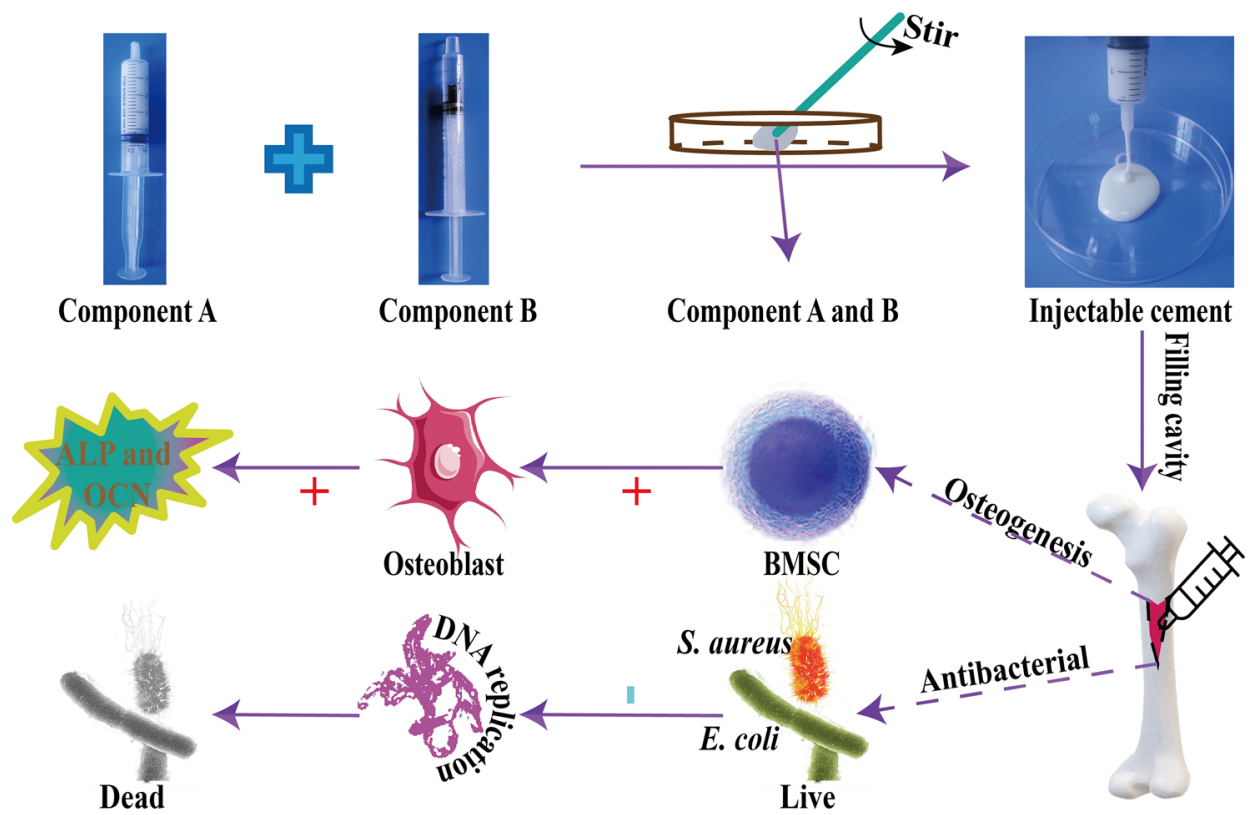


(a)

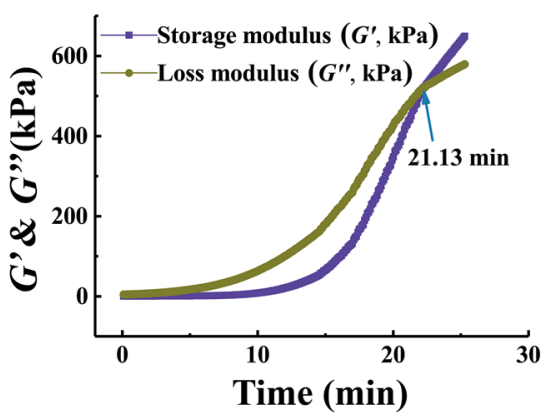

(d)

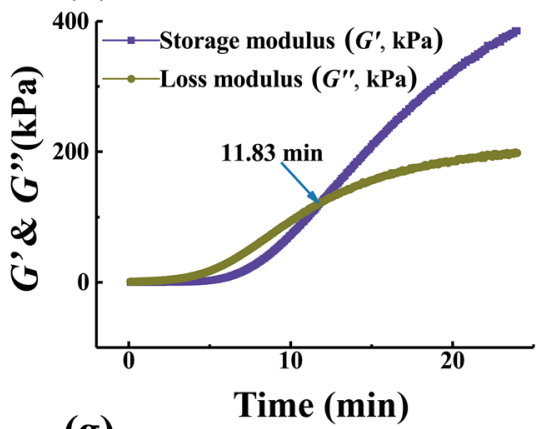

(g)

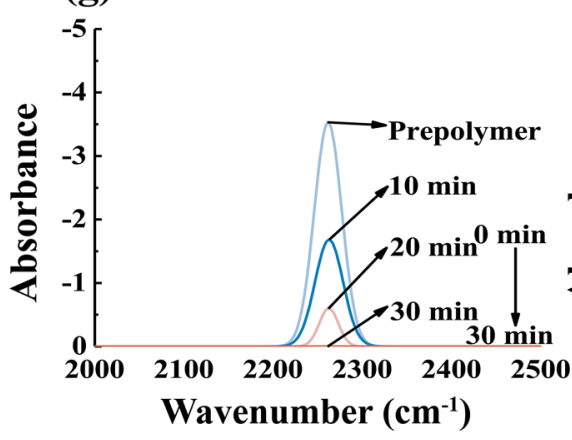

(b)

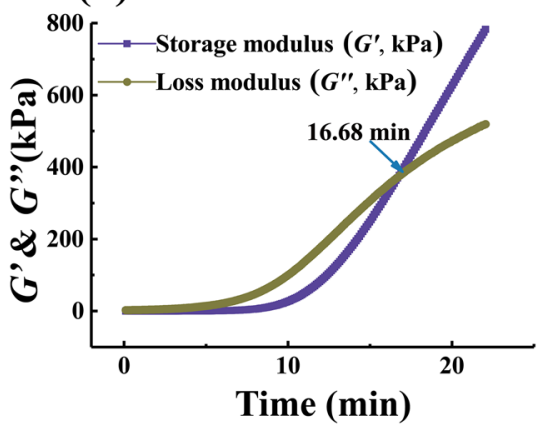

(e)

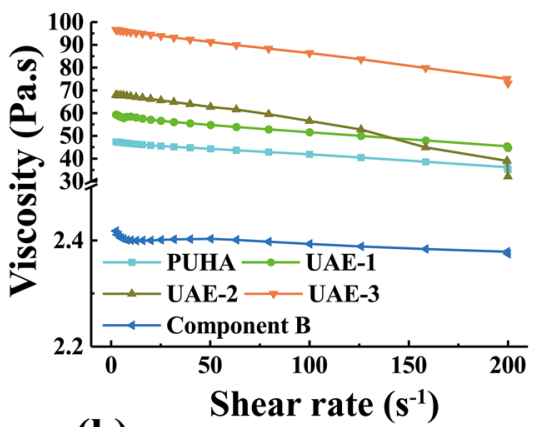

(h)

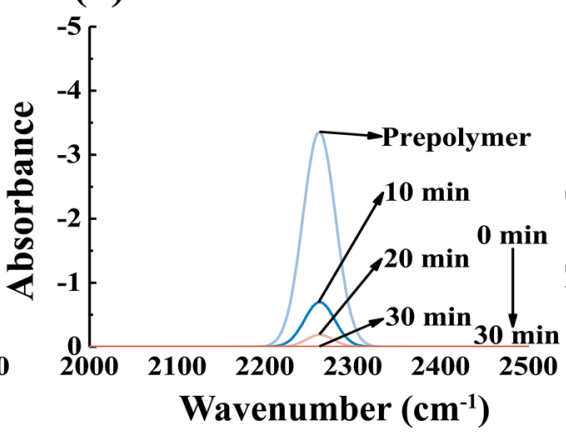

(c)

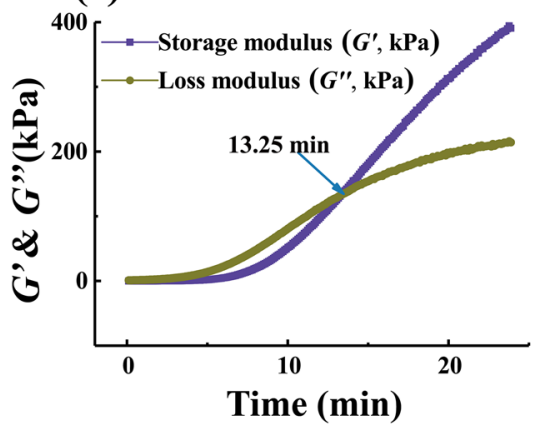

(f)

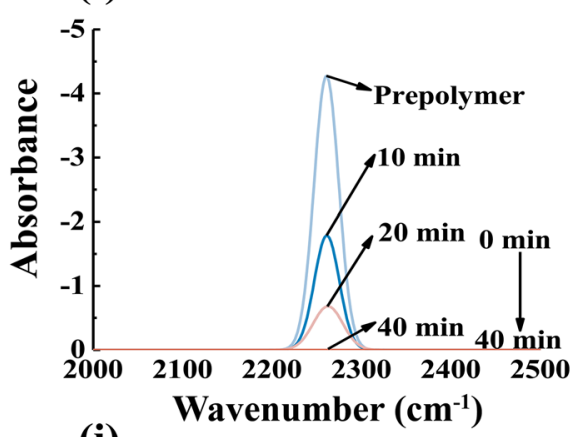

(i)

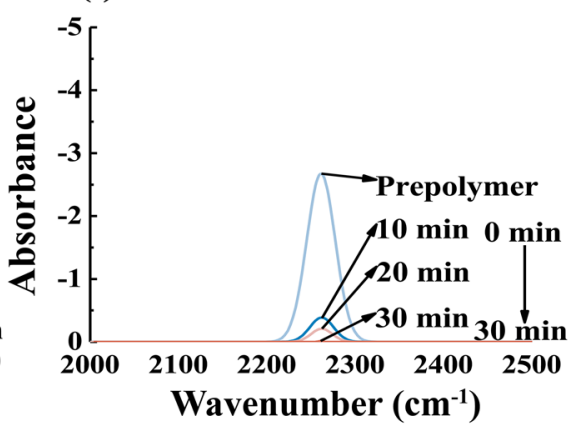

Fig. 2 Time-dependent functions of $G^{\prime}$ and $G^{\prime \prime}$ for curing PUHA (a), UAE-1 (b), UAE-2 (c) and UAE-3 (d), typical frequency-dependent functions of the viscosity of different composites (e), -NCO conversion rate for curing PUHA (f), UAE-1 (g), UAE-2 (h) and UAE-3 (i)

content of $-\mathrm{NCO}$ in the prepolymer of EN-loaded bone cement decreased with the increase of EN addition. This might be because that EN reagent would react with IPDI and consume an amount of -NCO during pre-polymerization process (see Fig. 4a for more details). The conversion rate of $-\mathrm{NCO}$ was accelerated with the presence of $\mathrm{EN}$, which matched the rheological results that the curing time became shorter. Meanwhile, the addition of EN did not influence the total conversion rate of -NCO. All -NCO groups of ENloaded cements was completely consumed at $30 \mathrm{~min}$ after curing. The monomer conversion of the PU cement is much higher than MMA-based cement [40], only about $75 \%$ at $35^{\circ} \mathrm{C}$. The high conversion of EN-loaded cement can avert the inflammation reaction of injectable materials in clinical application.

\subsection{Physiochemical Properties of the Cements}

The spectrum of the solid $\mathrm{C}^{13}$-NMR of the PUHA cement was displayed in Fig. 3a. The peak at 158 ppm (C-b) was corresponded to the urethane linkage [41]. The peaks at $71 \mathrm{ppm}$ may be a merged peak of the hard-segment carbons adjacent to the amino group $(\mathrm{C}-\mathrm{a})$ and methylidyne carbon adjacent to urethane $(\mathrm{C}-\mathrm{c})$ [28]. The presence of $\mathrm{C}-\mathrm{b}$ and $\mathrm{C}-\mathrm{c}$ demonstrated that the PTMEG and IPDI had a chemical reaction. The peak at $45 \mathrm{ppm}$ was associated with the methylene $(\mathrm{C}-\mathrm{d})$ of the six-membered ring in IPDI. In addition, the peaks ranging from 20 to $40 \mathrm{ppm}$ belonged to the saturated fatty carbons in both the soft segments and the hard segments [41]. The above results demonstrate that the PU was successfully synthesized. 
(a)

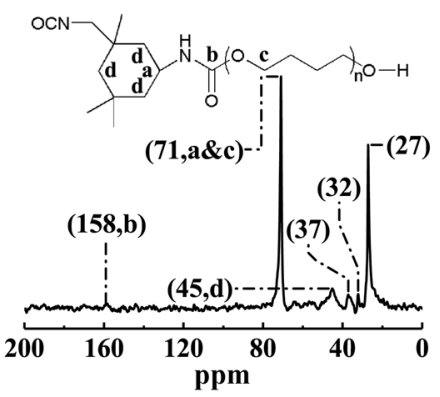

(d)
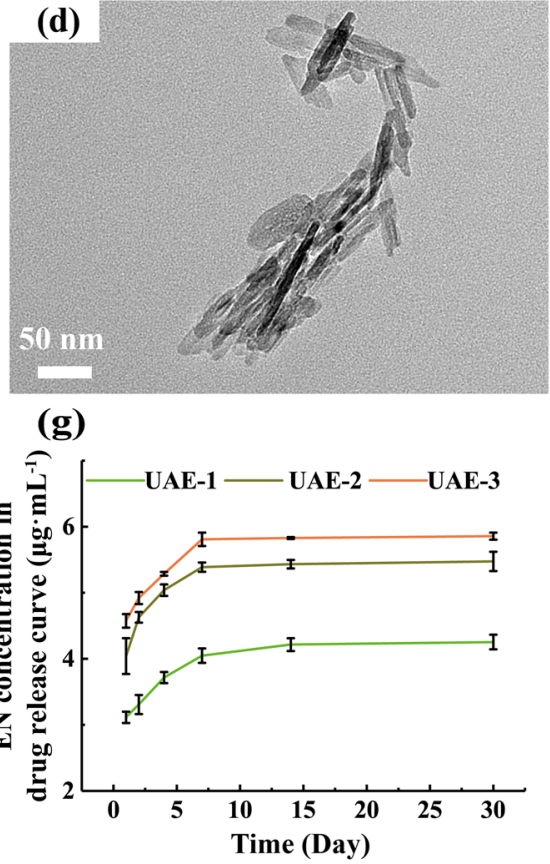

(b)

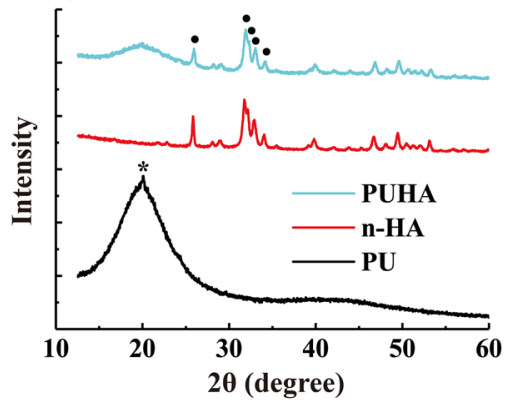

(e)

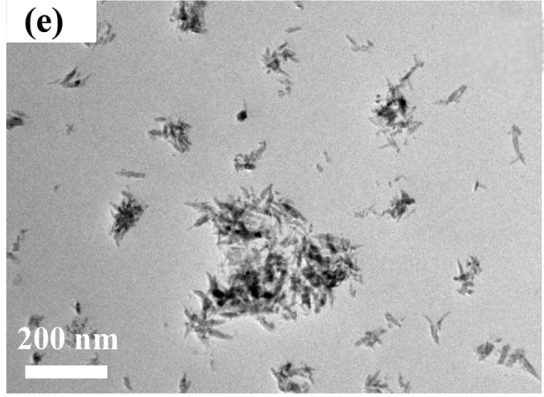

(h)

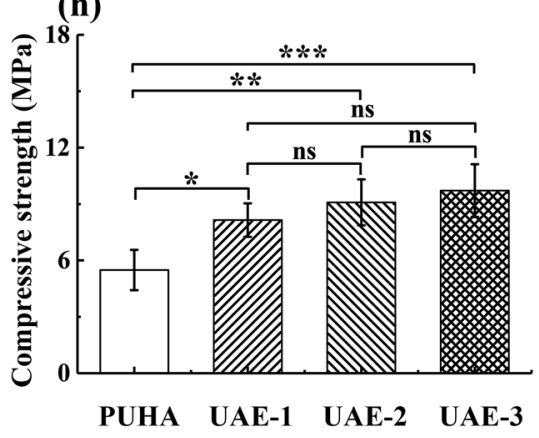

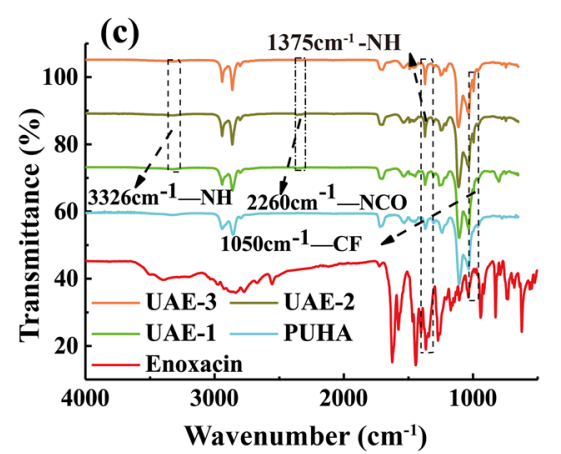

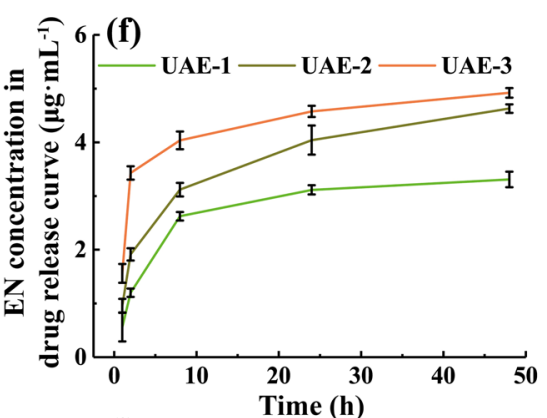

(i)

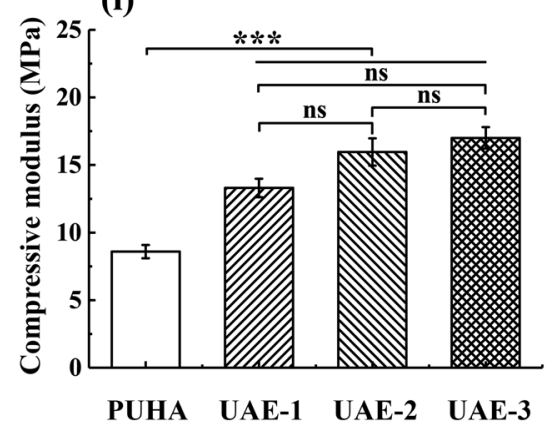

Fig. $3 \mathrm{C}^{13}$-NMR spectrum (a) of PUHA; the XRD spectra (b) of n-HA, PU and PUHA; (c) FTIR spectra of the EN, PUHA, and ENloaded cements; the TEM micrograph of the n-HA powder (d) and the PUHA composite (e); EN release curve for $48 \mathrm{~h}$ (f) and 30 days

As shown in Fig. 3b, the XRD spectrum of pure PU cement showed only an envelope spectrum with a broad peak centered at $20.1^{\circ}$, indicating the weak crystallized nature of the polymer [42]. On the other side, n-HA showed some sharp peaks, which indicated well crystallinity that were in good agreement with the JCPDS 09-0432. Five obvious diffraction peaks were at $25.8^{\circ}, 31.8^{\circ}, 32.2^{\circ}, 32.9^{\circ}$ and $34.9^{\circ}$, which were indexed to the (002), (211), (112), (300) and (202) planes of n-HA, respectively [43]. The composite of PUHA cement showed a combined pattern similar to the individual spectrum of PU and n-HA, except for a relative decrease in the intensity. In addition, the reason of the intensity decreases may be the n-HA particles were covered with the organic network. The XRD results indicated that n-HA particles were incorporated into PU matrix. (g); the compressive strength (h) and compressive modulus (i) of PUHA and EN-loaded bone cements. (“॰” indicates the crystalline phase of HA, "**" indicates poorly crystallized PU phase; $* p<0.05$, $* * p<0.01, * * * p<0.001,(n=5))$

The FTIR spectra could be used to confirm the chemical groups or linkages within a polymeric structure, which could determine whether a new substance was successfully synthesized at the molecular level. As shown in Fig. 3c, the appearance of bands at $3326 \mathrm{~cm}^{-1}(-\mathrm{NH})$ and the disappearance of the absorption peak at $2260 \mathrm{~cm}^{-1}$ (-NCO) synergistically proved that the PU was successfully synthesized. Furthermore, it was noteworthy that a new stretching vibration peak located at $1050 \mathrm{~cm}^{-1}(-\mathrm{C}-\mathrm{F})$ appeared in EN-loaded bone cement and strengthened as the content of EN increased, which demonstrated that the EN was successfully embedded into PU. In addition, the band at around $1365 \mathrm{~cm}^{-1}$ was the absorption peak of the amine group in PUHA. The $1365 \mathrm{~cm}^{-1}$ was shifted to $1375 \mathrm{~cm}^{-1}$ with the addition of EN. This redshift was because the amine group in PUHA was protonated by the piperazinyl 


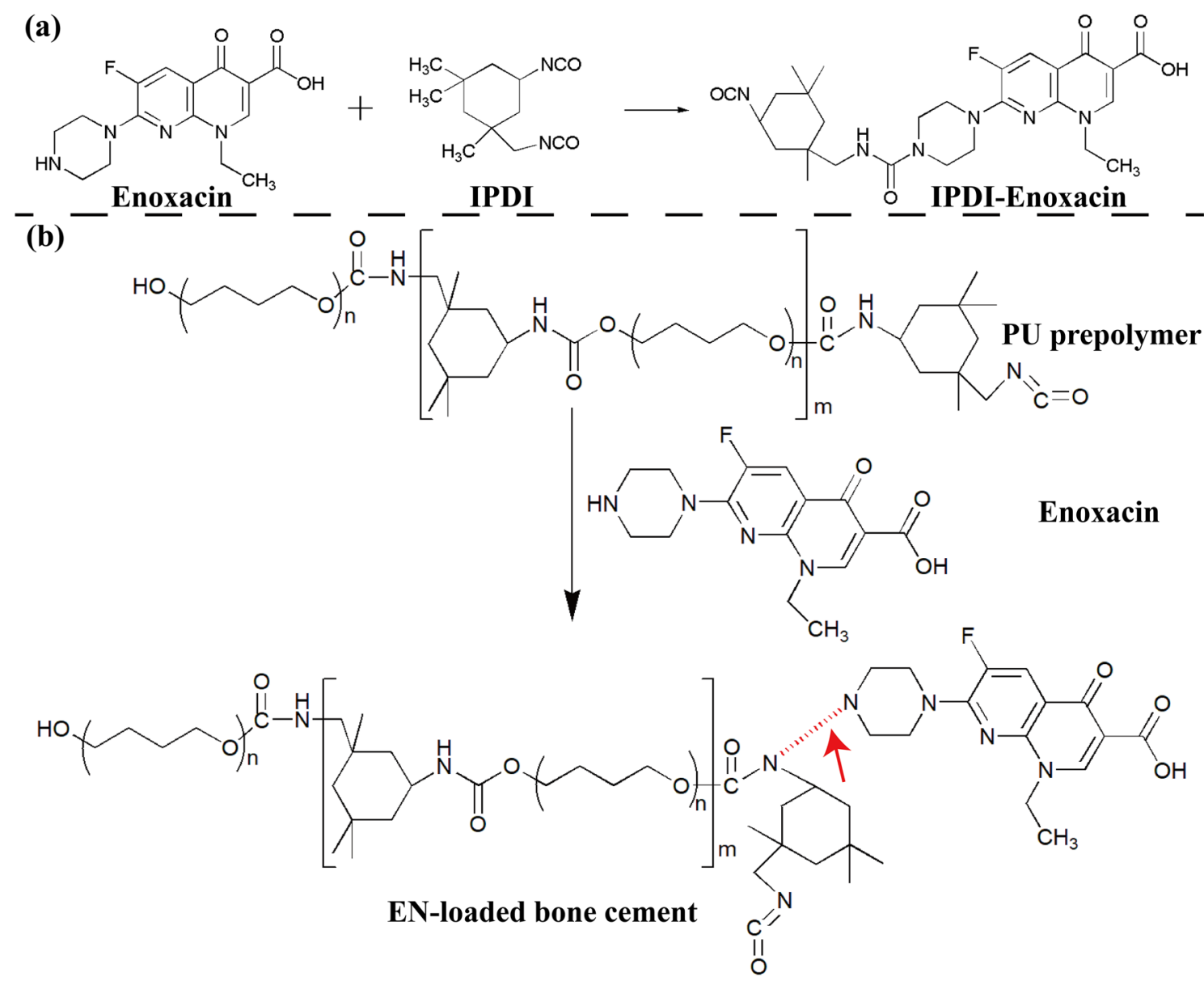

Fig. 4 a Possible mechanisms of EN molecule reacting with IPDI in prepolymer, b possible mechanisms of EN molecule participating in cured bone cement (Red arrow: electrostatic attraction between EN molecule and PU matrix)

group in EN molecule. The redshift about $10 \mathrm{~cm}^{-1}$ implied the presence of electrostatic attraction between EN molecule and PU matrix [44] (see details in Fig. 4b). Furthermore, the band at $1375 \mathrm{~cm}^{-1}$ was strengthened as the EN content increased. These implied that EN was successfully embedded into PU matrix.

As shown in Fig. 3d, the n-HA crystals synthesized by the chemical precipitation method were mostly in the shape of needles or rods, of which the crystal length was around $100 \mathrm{~nm}$ and the width was around $25 \mathrm{~nm}$. In addition, they are basically similar to the shape of natural bone apatite with good crystallinity. As shown in Fig. 3e, the TEM micrograph of PUHA composite was observed from the ultra section confirming the good dispersion of the rod-shaped nano crystals in the PU matrix.

Release behavior of antibiotic EN was studied shown in Fig. 3f, g. A burst release of EN was observed in the first $2 \mathrm{~h}$, and the drug concentration quickly reached at $2 \mu \mathrm{g} \cdot \mathrm{mL}^{-1}$, which was much higher than the MIC of EN. Subsequently, the drug release rate slowed down, and the drug was still released slowly until the 8th day. The concentration of EN at all release timepoints was greater than the MIC of EN $\left(0.8 \mu \mathrm{g} \cdot \mathrm{mL}^{-1}\right)$, showing the good potential of EN-loaded bone cement to inhibit bacterial proliferation. The ENloaded bone cement exhibited a slow-release characteristic as a whole, and the EN drug loading in this study was effective and reasonable. In addition, it could be seen that the EN release concentration was dose-dependent at all timepoints. The higher the drug loading content, the greater the concentration of EN released. The reason might be that PUHA was a non-degradable material with a dense structure, and the drug was loaded in a mixed manner before curing. Therefore, only the drug on the surface of PUHA could be released after curing. Therefore, the release concentration of EN presented a dose-dependent trend. On the other hand, BAI caused by implant surgery mostly originate from the implant interface [45]. The EN-loaded bone cement in this study could continuously and slowly release the antibacterial drug EN from the surface to inhibit bacterial proliferation.

The mechanical performances of cured bone cement are critical indicator that determines whether they have enough feasibility to be employed in bone tissue engineering. The 
compress stress versus strain (\%) graph of PUHA, UAE-1, UAE- 2 and UAE-3 were displayed in Fig. S1 in the supporting information. As shown in Fig. 3h, i, the compressive strength and compressive modulus of PUHA material were distinctly enhanced $(p<0.001)$ after incorporating EN component. It was worth noting that the compressive strength had the tendency to enhance with the increasement of EN content. The compressive strength of UAE-3 reached as high as $9.7 \pm 1.4 \mathrm{MPa}$, which was comparable to the high end of compressive strength of cancellous bone (2-10 MPa) [46]. This might result from the fact that EN acted as a crosslinking agent to promote the cross-linking between the soft and the hard segments through hydrogen bond [47], which matched the above FTIR results that the bands at $1365 \mathrm{~cm}^{-1}$ were strengthened with the presence of EN. However, there was no significant difference in the compression strength and modulus of UAE-1, UAE-2 and UAE-3. This reason might be the additive amount of EN was too small to show a significant difference.

\subsection{The Degree of Cross-Linking and Relative Properties}

In our previous study, cured pure PU was a stable and nondegradable materials, of which the solubility was $0.13 \pm 0.07 \%$ after $24 \mathrm{~h}$ soaking in water and the dimensional expansion was $1.39 \pm 0.38 \%$ after immersed in deionized water for 4 weeks [48]. A review has pointed that the presence of nano-particle, such as n-HA, would improve the stability and biocompatibility of polymer materials [49]. Here, shown in Table 2, the $S R$ of all drug-loaded PUHA cements were smaller, while the gel contents $(G)$ were larger than the PUHA cement when they were soaking in ethanol $(p<0.001)$. Both the $S R$ and $G$ results indicated that the EN drug improved the degree of cross-linking of cured PUHAs. Consequently, the presence of EN could enhance the stability of interior structure of PUHA cement, which also resulted the higher compressive property in Fig. 3h, i.

\subsection{Properties Influenced by the EN Loading}

As shown in Fig. 5a, b, the peak of F element in UAE-2 and UAE-3 was observed according to XPS results. EN is the only component containing $\mathrm{F}$ element in the synthesized bone cements. Besides, the peak of $\mathrm{F}$ element has the tendency to strehgthen when the content of EN increased. No distinct peak of $\mathrm{F}$ element in UAE-1 has been observed, because the EN content was too low. Hence, the XPS results testified that EN was successfully incorporated into PUHA matrix.

As shown in Fig. 5c, the EN concentration in extract solution of cured UAE-1, UAE-2 and UAE- 3 was measured, which was $22.38 \pm 3.73 \mu \mathrm{g} \cdot \mathrm{mL}^{-1}, 25.91 \pm 1.82 \mu \mathrm{g} \cdot \mathrm{mL}^{-1}$, $36.12 \pm 3.53 \mu \mathrm{g} \cdot \mathrm{mL}^{-1}$, respectively. Compared to EN concentration in release curve, the EN concentration in extract solution was much higher. This was because the extract solution was prepared by exposing the culture medium on the surface of the cured bone cement according to ISO 10993-9, which the volume-to-surface area proportion is $1.25 \mathrm{~cm}^{2} \cdot \mathrm{mL}^{-1}$ for $48 \mathrm{~h}$ at $37{ }^{\circ} \mathrm{C}$. It was prepared to evaluate the in vitro biological activity of the drug-loaded bone cements. All biological experiments in vitro were carried out in extract solution for a stable evaluation in this study.

SEM was used to observe the constituent of PUHA, UAE1, UAE-2 and UAE-3 in BSE mode, which were shown in Fig. S2 in the supporting information. Furthermore, as shown in Fig. 5d-k, the surface scanning by EDS showed that the characteristic elements $(\mathrm{Ca}$ and $\mathrm{P})$ were observed in PUHA, UAE-1, UAE-2, and UAE-3. The $\mathrm{Ca}$ and $\mathrm{P}$ were in the same position, which matched the SEM and TEM results that n-HA particles were observed.

\subsection{Antibacterial Properties}

\subsubsection{Zone of Inhibition (ZOI)}

The ZOI of EN-loaded bone cement against S. aureus and E. coli were exhibited in Fig. 6a, b. The antibacterial effect of EN-loaded bone cement is proportional to the area of antibacterial zone. In addition, the mean area of $\mathrm{ZOI}$ was presented in the form of histograms $(n=3)$. The inhibition circle could be observed around the EN-loaded bone cement sample. In addition, no bacteriostatic area has been observed around samples of pristine PUHA. Higher EN contents of cements exhibited larger inhibition zones against both two bacteria and the difference were significant $(p<0.01$ and $p<0.001)$.
Table 2 Physical properties of PUHA, UAE-1, UAE-2 and UAE-3

\begin{tabular}{llll}
\hline Cements & Swelling rate $(S R, \%)$ & Apparent density $\left(\rho, \mathrm{g} \cdot \mathrm{cm}^{-3}\right)$ & Gel content $(G, \%)$ \\
\hline PUHA & $145.80 \pm 3.58$ & $1.36 \pm 0.02$ & $96.86 \pm 0.47$ \\
UAE-1 & $126.61 \pm 2.30(@ @$ @ & $1.38 \pm 0.05(@ @ @)$ & $98.47 \pm 0.21(@ @ @)$ \\
UAE-2 & $123.59 \pm 3.04(@ @ @)$ & $1.41 \pm 0.12(@ @ @)$ & $98.49 \pm 0.22(@ @ @)$ \\
UAE-3 & $118.97 \pm 1.07(@ @ @)$ & $1.48 \pm 0.09(@ @ @)$ & $98.60 \pm 0.11(@ @ @ @)$ \\
\hline
\end{tabular}

$n=5$. “@”Denotes: significant difference from the PUHA, @@@ $p<0.001$ 


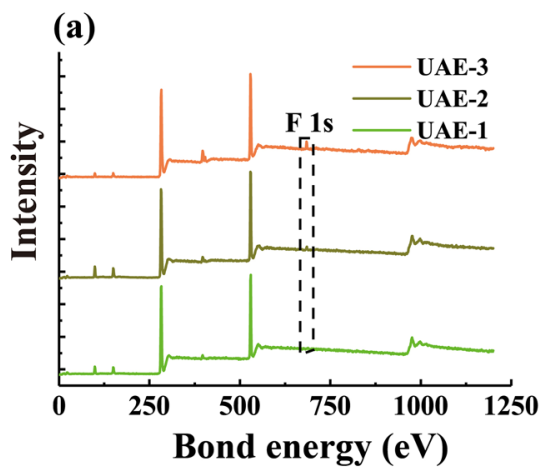

(d) PUHA

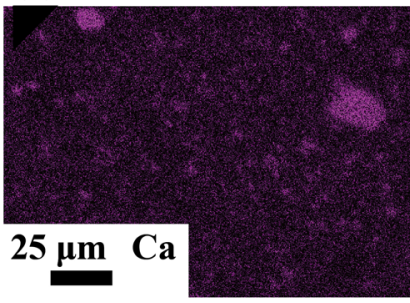

(h) PUHA

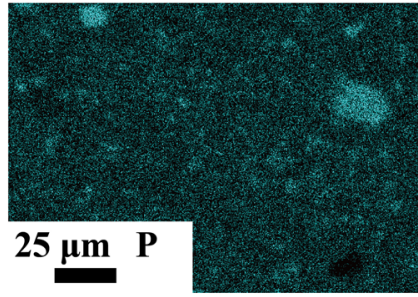

(e) UAE-1

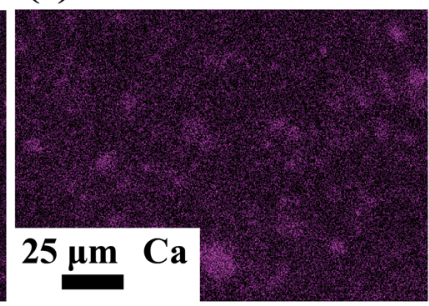

(i) UAE-1

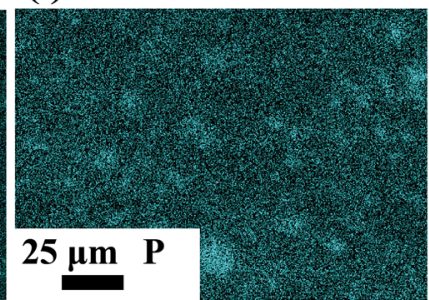

(b)

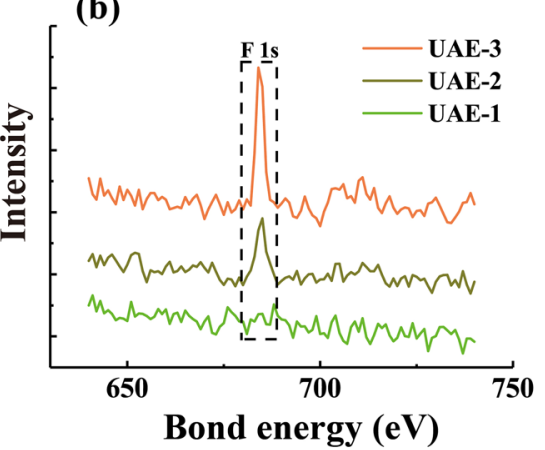

(f) $\mathrm{UAE}-2$

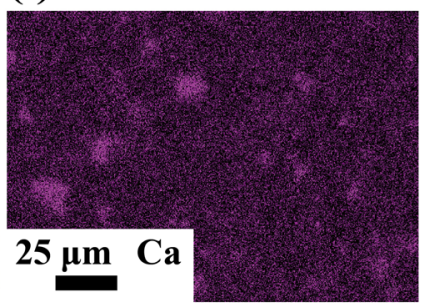

(j) UAE-2

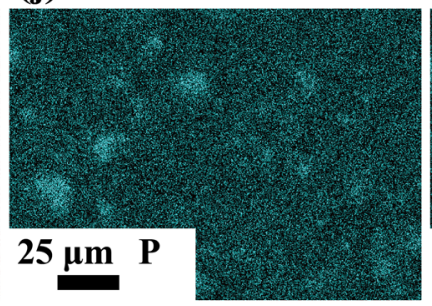

(c)

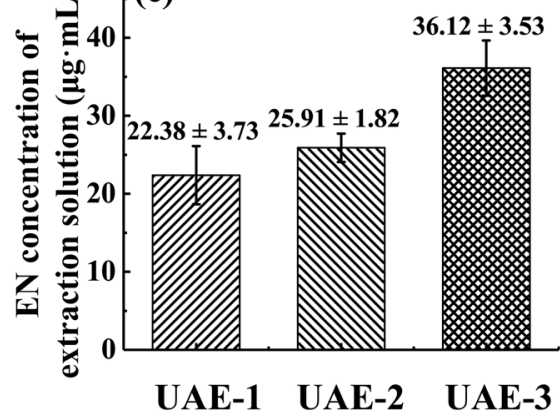

(g) UAE-3

Fig. 5 Full XPS spectra (a) and F $1 \mathrm{~s}$ spectra (b) of the drug-loaded cements; the EN concentration extracted $(n=5)$ from drug-loaded cements; distribution of $\mathrm{Ca}$ (purple, $\mathbf{d}-\mathbf{g}$ ) and $\mathrm{P}$ (green, $\mathbf{h}-\mathbf{k}$ ) elements on the surface scanning by EDS of PUHA, UAE-1, UAE-2 and UAE-3
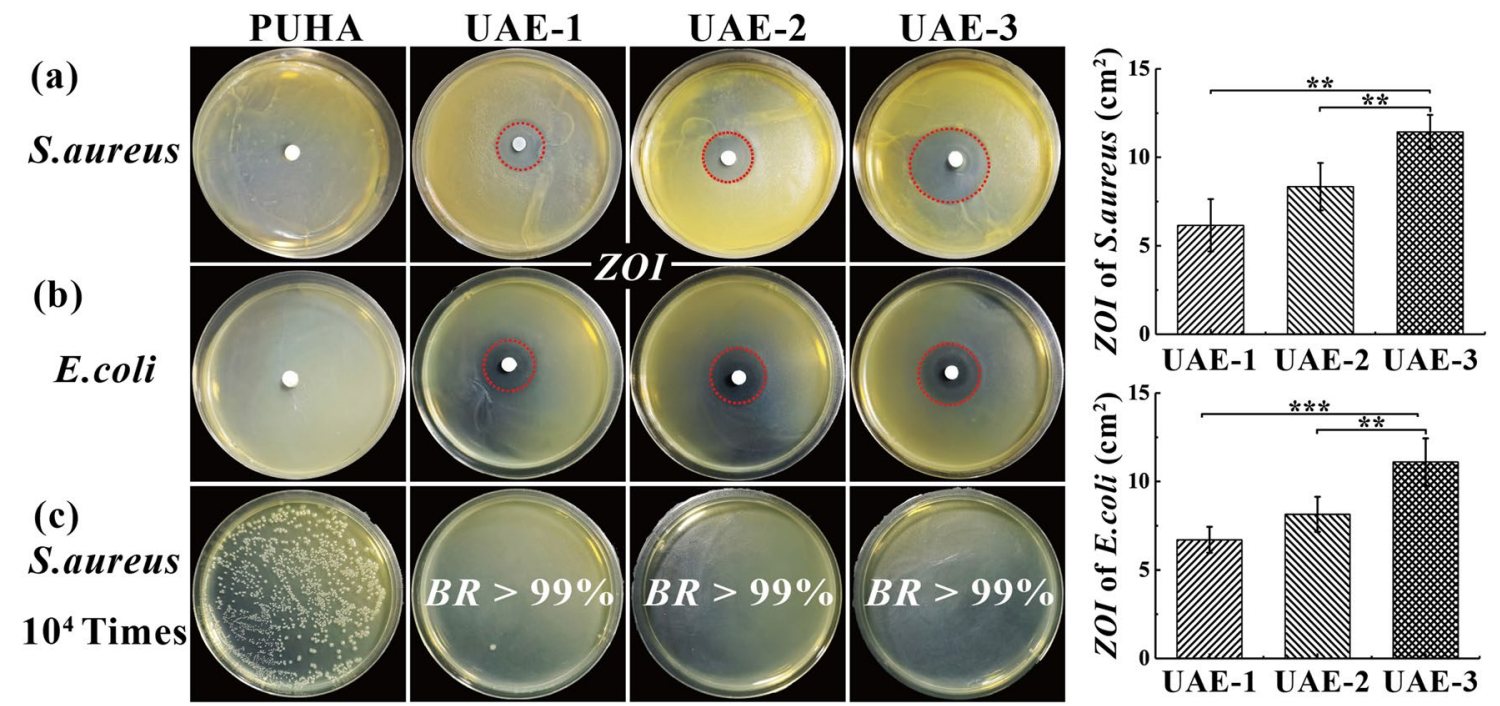

Fig. 6 Antibacterial performance of PUHA, UAE-1, UAE-2, and UAE-3. (* $p<0.05, * * p<0.01, * * * p<0.001), n=3$. (Red circles: antibacterial zones) 


\subsubsection{Bacteriostasis Rate (BR)}

As shown in Fig. 6c, S. aureus was employed to assess the BR of four types of bone cement. The BR test shows that there was rarely any colony left after $S$. aureus was cocultured with the EN-loaded bone cement samples. Nevertheless, approximately $400 \pm 35$ colonies were observed after $S$. aureus was cocultured with PUHA samples. The greater the BR value, the better the antibacterial effect. The BR could all even reach over 99\%, which indicated that all EN-loaded bone cements had the potential of anti-infection to inhibit bacteria proliferation effectively.

EN is a third-generation fluoroquinolones antibiotic, which can inhibit many kinds of bacterial due to its antibacterial mechanism, especially against Gram-positive bacteria (such as staphylococci and streptococci), those were the main reason causing BAI [25]. In addition, EN can influence the process of DNA replication of bacterial so that EN can kill bacterial rapidly at a low concentration $\left(\leq 0.8 \mu \mathrm{g} \cdot \mathrm{mL}^{-1}\right)$ [27]. Combined with the aforementioned drug burst and sustained release behavior, it could be seen that the EN-loaded bone cement had the property of quickly killing bacteria in the early stage and preventing BAI infection in the subsequent.

\subsection{In Vitro Biocompatibility}

\subsubsection{Cell Proliferation}

In general, the proliferation of BMSCs increased with the extension of culture time shown in Fig. 7a. It was worth noting that the OD value of UAE-1 and UAE-2 groups were significantly higher than those of the Ctrl group on the 4th and 7th day, indicating that both UAE-1 and UAE- 2 could promote the proliferation of BMSCs. However, there was no significant statistical difference between UAE-1 group and UAE-2 group. Compared with the Ctrl group, the OD value of the UAE-3 group did not show a statistically significant difference. It indicated that the three groups of bone cement had no obvious cytotoxicity. The difference between UAE-3 and the other EN-loaded bone cement might relate to the dose of EN. It was reported that low concentrations of EN were beneficial to promote cell proliferation [50], while EN concentrations greater than $32 \mu \mathrm{g} \cdot \mathrm{mL}^{-1}$ [51] could inhibit cell proliferation to a certain extent. In this study, bone cement extracts with different drug loading content were used, among which the concentrations of UAE-1 and UAE-2 were lower than $32 \mu \mathrm{g} \cdot \mathrm{mL}^{-1}$, and the concentration of UAE-3 was slightly higher (see Fig. $5 \mathrm{c}$ for details). Therefore, compared with UAE-1 and UAE-2, the UAE-3 group did not show the positive effect of promoting cell proliferation. Besides, the live BMSCs morphology was observed with Fluorescence microscope on day 7. In Fig. 7d, BMSCs of UAE- 1 and UAE-2 almost covered the entire field of view, while the cell density of the Ctrl and UAE-3 groups was lower. The BMSCs cultured in UAE-3 had a lower cell density and smaller morphology compared to BMSCs cultured in UAE-1 and UAE-2 groups, which was consistent with the result of CCK-8. In conclusion, the drug-loaded cements (UAE-1 and UAE-2 groups) had good biocompatibility, which exhibited great feasibility in the clinic.

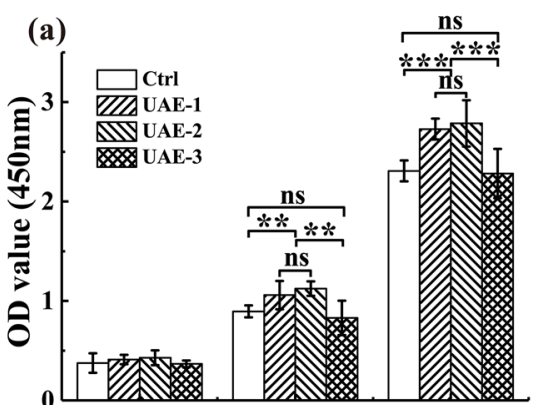

(d) Day 1

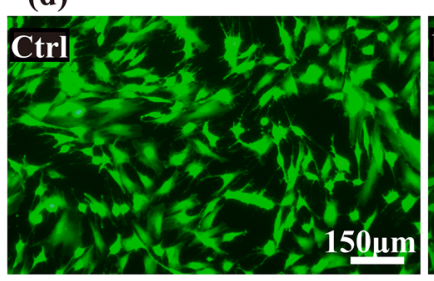

Day 7

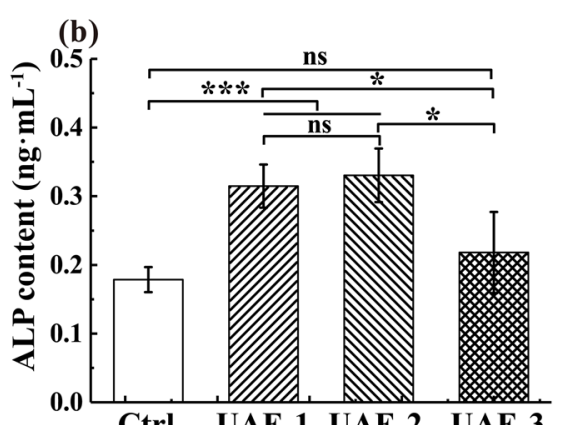

Ctrl UAE-1 UAE-2 UAE-3
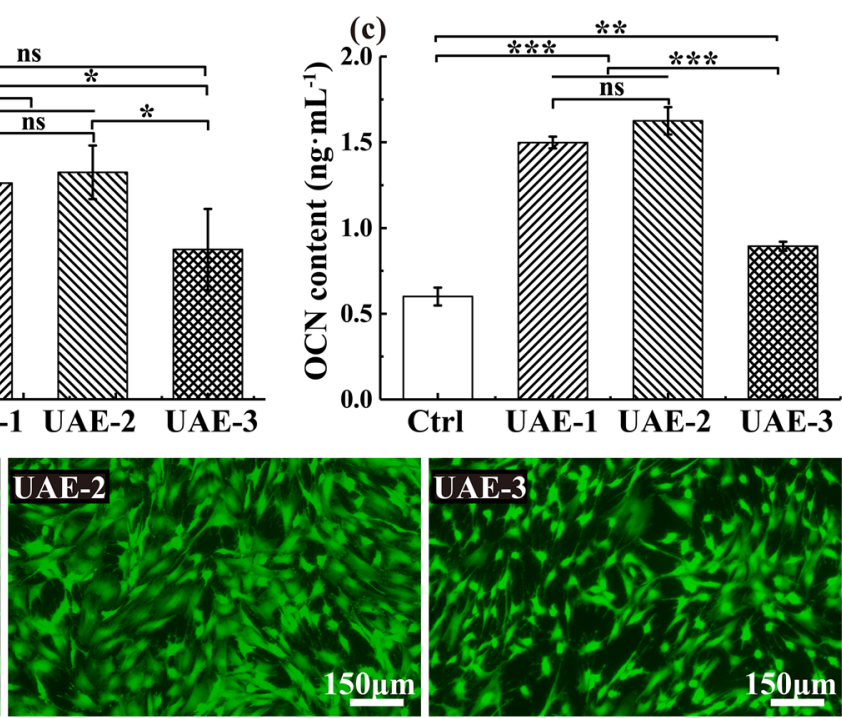

Fig. 7 CCK-8 (a), ALP (b) and OCN (c) results of BMSCs grown in Ctrl and extraction solutions of UAE-1, UAE-2, and UAE-3, respectively $(n=3)$. Fluorescence microscopy images (d) of BMSCs after culturing with $\alpha$-MEM medium and extraction solutions of ENloaded bone cements $\left(* p<0.05,{ }^{*} p<0.01,{ }^{*} * * p 0.001\right)$ 


\subsubsection{Cell Differentiation}

To evaluate the influence of materials on osteogenic differentiation, ALP and OCN were chosen as indicators of early and late osteogenic differentiation, respectively. As shown in Fig. 7b, c, the expression of ALP and OCN in the UAE-1 and UAE-2 groups was significantly higher than that in the Ctrl group, while there was no significant statistical difference between UAE-1 and UAE-2. However, the expression levels of ALP and OCN in the UAE- 3 group were significantly lower to those in the UAE- 1 and UAE-2 groups $(p<0.05$ and $p<0.001$ ). The weaker expression ALP and OCN in UAE-3 was similar with the CCK- 8 results. Similar with the cell proliferation, the expression of osteoblast-related protein also has been largely affected by the drug dosage. Due to the concentrations of extracts UAE- 1 and UAE- 2 were lower than $32 \mu \mathrm{g} \cdot \mathrm{mL}^{-1}$, they showed the positive effect on promoting osteogenic related proteins. However, the concentration of UAE-3 was slightly higher than $32 \mu \mathrm{g} \cdot \mathrm{mL}^{-1}$, so it did not show obvious promoting effect on osteogenic proteins expression. Ultimately, both UAE-1 and UAE-2 groups had excellent osteogenic properties. Especially for UAE-2 group, good potential has been expressed for promoting osteogenic differentiation with high antibacterial activity.

\section{Conclusions}

In this research, the EN-loaded injectable PUHA cements for BAI prevention were synthesized and characterized by physiochemical and biological experiment in vitro. The antibacterial cements showed a good viscosity and injectability by shear-thinning behavior for convenient manipulation. The addition of EN drug speeded up the conversion of monomers and increased the cross-linking and mechanical properties that enhanced the stability of the cured EN-loaded cements, which is benefit to avoid the inflammation reaction caused by residual monomers. All drug-loaded PUHA cements showed a perfect antibacterial property, while the UAE-3 group did not present good biological response of cell proliferation and differentiation because of high drug dose loading. From the above, the UAE-2 is the promising substitute as anti-infection bone cement with suitable physical properties, antibacterial and in vitro biological properties, which in vivo efficiency would be evaluated in next study.

Supplementary Information The online version contains supplementary material available at https://doi.org/10.1007/s42235-021-00144-2.

Acknowledgements This study was funded by the Sichuan International Science and Technology Innovation Cooperation Project [Grant Numbers 2021YFH0122] and the Fundamental Research Funds for the Central Universities. We would like to thank Hui Wang, Jiqiu Wen, Yuanming Zhai and Suilin Liu (Analytical \& Testing Center of Sichuan
University) for her help of SEM images, XRD spectra, $C^{13}$-NMR spectrum and XPS analysis, respectively.

\section{Declarations}

Conflict of interest The authors have no competing interests to declare that are relevant to the content of this article.

Open Access This article is licensed under a Creative Commons Attribution 4.0 International License, which permits use, sharing, adaptation, distribution and reproduction in any medium or format, as long as you give appropriate credit to the original author(s) and the source, provide a link to the Creative Commons licence, and indicate if changes were made. The images or other third party material in this article are included in the article's Creative Commons licence, unless indicated otherwise in a credit line to the material. If material is not included in the article's Creative Commons licence and your intended use is not permitted by statutory regulation or exceeds the permitted use, you will need to obtain permission directly from the copyright holder. To view a copy of this licence, visit http://creativecommons.org/licenses/by/4.0/.

\section{References}

1. Stromsoe, K. (2004). Fracture fixation problems in osteoporosis. Injury, 35, 107-113.

2. Steinmetz, S., Wernly, D., Moerenhout, K., Trampuz, A., \& Borens, O. (2019). Infection after fracture fixation. EFORT Open Reviews, 4, 468-475.

3. Henkelmann, R., Frosch, K. H., Glaab, R., Lill, C., Seybold, D., Josten, C., \& Hepp, P. (2017). Infection following fractures of the proximal tibia-A systematic review of incidence and outcome. BMC Musculoskeletal Disorders, 18, 481-489.

4. von Rüden, C., \& Augat, P. (2016). Failure of fracture fixation in osteoporotic bone. Injury, 47, S3-S10.

5. Herrera-Perez, M., Diaz-Fernandez, R., Rendon-Diaz, D., Boluda-Mengod, J., Pais-Brito, J. L., \& Tejero, S. (2020). Tibiotalocalcaneal fusion with antibiotic cement-coated nails for refractory deep infection after ankle ORIF. Foot Ankle International, 41, 1391-1397.

6. Sánchez-Fernández, M. J., Hammoudeh, H., Félix Lanao, R. P., van Erk, M., van Hest, J. C. M., \& Leeuwenburgh, S. C. G. (2019). Bone-adhesive materials: Clinical requirements, mechanisms of action, and future perspective. Advanced Materials Interfaces, 6, 1802021-1802031.

7. Starr, A. J. (2008). Fracture repair: Successful advances, persistent problems, and the psychological burden of trauma. Journal of Bone and Joint Surgery-American, 90A, 132-137.

8. Boner, V., Kuhn, P., Mendel, T., \& Gisep, A. (2009). Temperature evaluation during PMMA screw augmentation in osteoporotic bone-An in vitro study about the risk of thermal necrosis in human femoral heads. Journal of Biomedical Materials Research B Applied Biomaterials, 90, 842-848.

9. Kim, S. B., Kim, Y. J., Yoon, T. L., Park, S. A., Cho, I. H., Kim, E. J., Kim, I. A., \& Shin, J. W. (2004). The characteristics of a hydroxyapatite-chitosan-PMMA bone cement. Biomaterials, $25,5715-5723$.

10. Jayabalan, M., Shalumon, K. T., \& Mitha, M. K. (2009). Injectable biomaterials for minimally invasive orthopedic treatments. Journal of Materials Science: Materials in Medicine, 20, 1379-1387.

11. Mohammadi, M., Hesaraki, S., \& Hafezi-Ardakani, M. (2014). Investigation of biocompatible nanosized materials for 
development of strong calcium phosphate bone cement: Comparison of nano-titania, nano-silicon carbide and amorphous nanosilica. Ceramics International, 40, 8377-8387.

12. Li, J., Celiz, A. D., Yang, J., Yang, Q., Wamala, I., Whyte, W., Seo, B. R., Vasilyev, N. V., Vlassak, J. J., Suo, Z., \& Mooney, D. J. (2017). Tough adhesives for diverse wet surfaces. Science, 357, 378-381.

13. Esnaashary, M. H., Karfarma, M., Rezaie, H. R., Khavandi, A., \& Javadpour, J. (2021). The comparative study of Gelatin/CNT-contained $\mathrm{Mg}-\mathrm{Ca}-\mathrm{P}$ bone cement with the Plain and CNT-reinforced ones. Journal of Bionic Engineering, 18, 623-636.

14. Greish, Y., Attia, N., \& Mourad, A.-H. (2018). Formation and biomimetic deposition of bone-like hydroxyapatite on Wollastonitegypsum composites. Journal of Bionic Engineering, 15, 894-906.

15. Janik, H., \& Marzec, M. (2015). A review: Fabrication of porous polyurethane scaffolds. Materials Science and Engineering $C$ : Materials For Biological Applications, 48, 586-591.

16. Ji, F. L., Hu, J. L., Li, T. C., \& Wong, Y. W. (2007). Morphology and shape memory effect of segmented polyurethanes. Part I: With crystalline reversible phase. Polymer, 48, 5133-5145.

17. Tenorio-Alfonso, A., Sánchez, M. C., \& Franco, J. M. (2020). A review of the sustainable approaches in the production of biobased polyurethanes and their applications in the adhesive field. Journal of Polymers and the Environment, 28, 749-774.

18. Szycher, M. (2012). Polyurethane adhesives. In M. Szycher (Ed.),Szycher's Handbook of Polyurethanes (pp. 393-416). CRC Press.

19. Li, K. K., Zuo, Y., Zou, Q., Lin, L. L., Wang, L., Yang, B. Y., Hu, F., Li, J. J., Li, Y. B., \& Li, J. D. (2016). Synthesis and characterization of injectable nano-hydroxyapatite/polyurethane composite cement effective formulations for management of osteoporosis. Journal of Nanoscience and Nanotechnology, 16, 12407-12417.

20. Mei, Q. J., Lin, L. L., Wang, J., Cai, B., Zou, Q., Li, J. D., Li, Y. B., \& Zuo, Y. (2019). Chemical reaction kinetics and the characteristic properties of injectable adhesives of nano-hydroxyapatite/Ag3PO4/ polyurethane for bone and tooth repair. SN Applied Sciences, 1, 746-763.

21. Hajipour, M. J., Fromm, K. M., Ashkarran, A. A., Jimenez de Aberasturi, D., de Larramendi, I. R., Rojo, T., Serpooshan, V., Parak, W. J., \& Mahmoudi, M. (2012). Antibacterial properties of nanoparticles. Trends in Biotechnology, 30, 499-511.

22. von Nussbaum, F., Brands, M., Hinzen, B., \& Weigand, S. (2006). Antibacterial natural products in medicinal chemistry-exodus or revival? Angewandte Chemistry International Edition in English, $45,5072-5129$.

23. Saidin, S., Jumat, M. A., Mohd Amin, N. A. A., \& Saleh Al-Hammadi, A. S. (2021). Organic and inorganic antibacterial approaches in combating bacterial infection for biomedical application. Materials Science and Engineering C: Materials for Biological Applications, 118, 111382-111399.

24. Clarke, A. L., De Soir, S., \& Jones, J. D. (2020). The safety and efficacy of phage therapy for bone and joint infections: A systematic review. Antibiotics (Basel), 9, 795-805.

25. Anderson, J. M., \& Marchant, R. E. (2000). Biomaterials: Factors favoring colonization and infection. In F. A. Waldvogel \& A. L. Bisno (Eds.), Infections associated with indwelling medical devices (pp. 89-109). ASM Press.

26. Wiles, J. A., Bradbury, R. J., \& Pucci, R. J. (2010). New quinolone antibiotics: A survey of the literature from 2005 to 2010. Expert Opinion on Therapeutic Patents, 20, 1295-1319.

27. Bedard, J., \& Bryan, L. E. (1989). Interaction of the fluoroquinolone antimicrobial agents ciprofloxacin and enoxacin with liposomes. Antimicrobial Agents and Chemotherapy, 33, 1379-1382.

28. Li, L. M., Zuo, Y., Zou, Q., Yang, B. Y., Lin, L. L., Li, J. D., \& Li, Y. B. (2015). Hierarchical structure and mechanical improvement of an n-HA/GCO-PU composite scaffold for bone regeneration. ACS Applied Materials Interfaces, 7, 22618-22629.

29. Wang, L., Heuchel, M., Fang, L., Kratz, K., \& Lendlein, A. (2012). Influence of a polyester coating of magnetic nanoparticles on magnetic heating behavior of shape-memory polymer-based composites. Journal of Applied Biomaterials \&amp; Functional Materials, 10, 203-209.

30. Sayed, M., Arooj, A., Shah, N. S., Khan, J. A., Shah, L. A., Rehman, F., Arandiyan, H., Khan, A. M., \& Khan, A. R. (2018). Narrowing the band gap of $\mathrm{TiO}_{2}$ by co-doping with $\mathrm{Mn}^{2+}$ and $\mathrm{Co}^{2+}$ for efficient photocatalytic degradation of enoxacin and its additional peroxidase like activity: A mechanistic approach. Journal of Molecular Liquids, 272, 403-412.

31. Bo, Y., Jiang, Y. J., Chen, K. M., Cai, K. M., Li, W. M., Roy, J., Bao, Y., \& Cheng, J. J. (2020). Targeting infected host cells in vivo via responsive azido-sugar mediated metabolic cell labeling followed by click reaction. Biomaterials, 238, 119843-119853.

32. Lin, L. L., Shao, J. L., Ma, J. Q., Zou, Q., Li, J. D., Zuo, Y., Yang, F., \& Li, Y. B. (2019). Development of ciprofloxacin and nanohydroxyapatite dual-loaded polyurethane scaffolds for simultaneous treatment of bone defects and osteomyelitis. Materials Letters, 253, 86-89.

33. Lu, C. C., Chou, S. H., Shen, P. C., Chou, P. H., Ho, M. L., \& Tien, Y. C. (2020). Extracorporeal shock wave promotes activation of anterior cruciate ligament remnant cells and their paracrine regulation of bone marrow stromal cells' proliferation, migration, collagen synthesis, and differentiation. Bone Joint Resesrch, 9, 458-468.

34. Golub, E. E., Harrison, G., Taylor, A. G., Camper, S., \& Shapiro, I. M. (1992). The role of alkaline phosphatase in cartilage mineralization. Bone and Mineral, 17, 444-448.

35. Zoch, M. L., Clemens, T. L., \& Riddle, R. C. (2016). New insights into the biology of osteocalcin. Bone, 82, 42-49.

36. No, Y. J., Roohani-Esfahani, S. I., \& Zreiqat, H. (2014). Nanomaterials: The next step in injectable bone cements. Nanomedicine (London, England), 9, 1745-1764.

37. Avery, R. K., Albadawi, H., Akbari, M., Zhang, Y. S., Duggan, M. J., Sahani, D. V., Olsen, B. D., Khademhosseini, A., \& Oklu, R. (2016). An injectable shear-thinning biomaterial for endovascular embolization. Science Translational Medicine, 8, 365ra156-365ra157.

38. Wood, D., \& Hill, R. (1991). Glass ceramic approach to controlling the properties of a glass-ionomer bone cement. Biomaterials, 12, $164-170$.

39. Loeffel, M., Ferguson, S. J., Nolte, L. P., \& Kowal, J. H. (2008). Vertebroplasty: Experimental characterization of polymethylmethacrylate bone cement spreading as a function of viscosity, bone porosity, and flow rate. Spine, 33, 1352-1359.

40. Vallo, C. I. (2002). Theoretical prediction and experimental determination of the effect of mold characteristics on temperature and monomer conversion fraction profiles during polymerization of a PMMA-based bone cement. Journal of Biomedical Materials Research, 63, 627-642.

41. Hosseinpourpia, R., Echart, A. S., Adamopoulos, S., Gabilondo, N., \& Eceiza, A. (2018). Modification of pea starch and dextrin polymers with isocyanate functional groups. Polymers (Basel), 10, 939-950.

42. Qidwai, M., Sheraz, M. A., Ahmed, S., Alkhuraif, A. A., \& ur Rehman, I. (2014). Preparation and characterization of bioactive composites and fibers for dental applications. Dental Materials, 30, e253-263.

43. Lin, L. L., Ma, J. Q., Mei, Q. J., Cai, B., Chen, J., Zuo, Y., Zou, Q., Li, J. D., \& Li, Y. B. (2018). Elastomeric polyurethane foams incorporated with nanosized hydroxyapatite fillers for plastic reconstruction. Nanomaterials (Basel), 8, 972-985.

44. Choi, Y., Nirmala, R., Lee, J. Y., Rahman, M., Hong, S.-T., \& Kim, H. Y. (2013). Antibacterial ciprofloxacin $\mathrm{HCl}$ incorporated 
polyurethane composite nanofibers via electrospinning for biomedical applications. Ceramics International, 39, 4937-4944.

45. Gristina, A. G., \& Costerton, J. W. (1985). Bacterial adherence to biomaterials and tissue. The significance of its role in clinical sepsis. JBJS, 67, 264-273.

46. Gibson, L. J. (1985). The mechanical behaviour of cancellous bone. Journal of Biomechanics, 18, 317-328.

47. Mulas, K., Stefanowicz, Z., Oledzka, E., \& Sobczak, M. (2019). Current state of the polymeric delivery systems of fluoroquinolones - A review. Journal of Controlled Release, 294, 195-215.

48. Sun, B., Zuo, Y., Li, J. D., Wang, L., Tang, K. Y., Huang, D., Du, J. J., Luo, P. P., \& Li, Y. B. (2013). High conversion self-curing sealer based on a novel injectable polyurethane system for root canal filling. Materials Science and Engineering C: Materials For Biological Applications, 33, 3138-3145.

49. Szczepanczyk, P., Szlachta, M., Zlocista-Szewczyk, N., Chlopek, J., \& Pielichowska, K. (2021). Recent developments in polyurethane-based materials for bone tissue engineering. Polymers (Basel), 13, 946-981.
50. Li, H., Nie, B. E., Zhang, S. T., Long, T., \& Yue, B. (2019). Immobilization of type I collagen/hyaluronic acid multilayer coating on enoxacin loaded titania nanotubes for improved osteogenesis and osseointegration in ovariectomized rats. Colloids and Surfaces B Biointerfaces, 175, 409-420.

51. Ostrov, D. A., Magis, A. T., Wronski, T. J., Chan, E. K., Toro, E. J., Donatelli, R. E., Sajek, K., Haroun, I. N., Nagib, M. I., Piedrahita, A., Harris, A., \& Holliday, L. S. (2009). Identification of enoxacin as an inhibitor of osteoclast formation and bone resorption by structure-based virtual screening. Journal of Medical Chemistry, 52, $5144-5151$.

Publisher's Note Springer Nature remains neutral with regard to jurisdictional claims in published maps and institutional affiliations. 